\title{
Spread of bovine herpesvirus type 5 (BHV-5) in the rabbit brain after intranasal inoculation
}

\author{
Bong J Lee ${ }^{1}$, Mark L Weiss ${ }^{2}$, Derek Mosier ${ }^{1}$ and Shafiqul I Chowdhury*,1 \\ ${ }^{1}$ Department of Diagnostic Medicine/Pathobiology, College of Veterinary Medicine, Kansas State University, Manhattan, \\ Kansas, KS 66506, USA; ${ }^{2}$ Department of Anatomy and Physiology, College of Veterinary Medicine, Kansas State \\ University, Manhattan, Kansas, KS 66506, USA
}

\begin{abstract}
Following intranasal inoculation of wild-type BHV-5 in rabbits, we studied the sequential transneuronal passage of the virus in the CNS by immunocytochemistry, histopathology, and virus isolation. At 4 and 6 days postinfection (d.p.i.), rabbits had no or mild neurological signs, and virus was isolated only from the olfactory bulbs. At 8 and 9 d.p.i., infected rabbits had severe neurological signs, and virus could be isolated from multiple regions of the brain segments. In these rabbits, high titers of virus were consistently present in the anterior and posterior cortices, including frontal, piriform/entorhinal, temporal, parietal, and occipital cortices, the hippocampus and the amygdala. Virus was isolated occasionally from the midbrain/diencephalon and pons/medulla. Virus was not isolated from the cerebellum and trigeminal ganglion of rabbits examined from 2-12 d.p.i. Immunocytochemistry revealed virus-specific antigens at 4 d.p.i. within the glomerular layer, external plexiform layer, and mitral cell layer of the main olfactory bulb. At 6 d.p.i., virus-specific antigens were also present within the inner granular layer of the main olfactory bulb. At 8 and 9 d.p.i., widespread BHV-5-specific staining occurred in the areas of the brain connected to the main olfactory bulb, including the frontal/cingulate cortex, anterior olfactory nucleus, lateral olfactory tubercle, piriform/entorhinal cortex, hippocampus, amygdala, dorsal raphe, and locus coeruleus. In the trigeminal ganglion, specific staining was detected within a few neurons at 2, 4, 6,8 d.p.i. However, further spread of the virus along the trigeminal pathway was not evident. These data indicate that $\mathrm{BHV}-5$ replicates and spreads preferentially in the olfactory pathway following intranasal instillation and that this viral spread correlated with the severity of neurological symptoms and histopathological lesions.
\end{abstract}

Keywords: BHV-5; neuropathogenesis; CNS-invasion; neurovirulence

\section{Introduction}

Bovine herpesvirus type 5 (BHV-5) is a neurovirulent alphaherpesvirus (d'Offay et al, 1993). Experimental intranasal inoculation with BHV-5 results in severe neurological signs in young calves between 9-10 days postinoculation (d.p.i.) (Belknap et al, 1994). The virus initially replicates in the olfactory and/or nasal epithelium and subsequently spreads to the central nervous system (CNS) to cause a severe, often fatal, encephalitis in calves (Belknap et al, 1994). Nonneurovirulent BHV-1 and neurovirulent BHV-5 infections can be distinguished

${ }^{*}$ Correspondence: SI Chowdhury

Received 22 January 1999; revised 22 March 1999; accepted 8 April 1999 based on their differential neuropathogenesis in a rabbit seizure model (Chowdhury et al, 1997). In this model, intranasal inoculation of rabbits with BHV-5 causes acute neurological signs that are comparable to those seen in calves. In the brains of infected rabbits, neuronal damage is located preferentially within the hippocampus formation and the piriform/entorhinal and frontal cortices. Virus-specific antigens and nucleic acid are detectable in these affected regions of the brain (Chowdhury et al, 1997).

The nasal and olfactory epithelia are innervated by three different types of neurons: (1) Olfactory receptor neurons, located in the olfactory epithelium, are the first order bipolar neurons. They have dendrites directly in contact with external medium and their axons project to several groups of neurons, 
primarily in the main olfactory bulb (Switzer et al, 1985); (2) parasympathetic motor neurons in the pterygopalatine (or sphenopalatine) ganglia have axonal connections with the superior salivatory nucleus in the medulla oblongata (Contreras et al, 1980; Spencer et al, 1990); (3) primary sensory neurons in the trigeminal ganglion have connections with neurons of the pontine and spinal trigeminal nuclei (Sp5) in the pons and medulla oblongata, respectively (Tracey, 1985).

Herpes simplex virus (HSV), pseudorabies virus (PRV), and rabies virus enter the CNS via both the olfactory and trigeminal nerves after intranasal inoculation (Barbic et al, 1994; Kritas et al, 1994a,b; Lafay et al, 1991; Martin and Dolivo, 1983; Stroop et al, 1984; Tomlinson and Esiri, 1983). Additionally, HSV-1 and PRV can enter the CNS via the ophthalmic branch of the trigeminal nerve after corneal inoculation (Knotts et al, 1974; Martin and Dolivo, 1983; Stroop et al, 1984). Following intranasal instillation of vesicular stomatitis virus (VSV) in mice, invasion of the CNS occurred via the olfactory pathway but not the trigeminal pathway (Lundh et al, 1987).

Our previous studies suggested that the olfactory pathway is more susceptible than the trigeminal pathway to the spread of BHV-5 after intranasal inoculation of rabbits (Chowdhury et al, 1997). In those experiments, rabbits were euthanized after they showed severe neurological signs, usually 8 10 days after virus inoculation. Thus, the systematic progression of BHV-5 infection in the CNS after the virus inoculation was not observed. The purpose of the present study was to map the systemic spread of BHV-5 in the rabbit nervous system after intranasal inoculation. For this purpose, the penetration, spread, and propagation of BHV-5 within the CNS were evaluated at different postinoculation times by immunocytochemistry, histopathology, and virus isolation.

\section{Results}

\section{Clinical signs of disease}

The two rabbits sacrificed at 2 d.p.i. did not have any clinical signs. Rabbits sacrificed at 4 and 6 d.p.i. had mild neurological signs characterized by hyperaesthesia, head-twitching and/or trembling. At 8 d.p.i., four rabbits were sacrificed that had severe neurological signs, which consisted of seizures/convulsion, upright sitting posture, circular movement, and opisthotonus. The seizures occurred at 5-10-min intervals and lasted for $1-$ 2 min. At 9 d.p.i., one rabbit had seizures and was sacrificed, and one was found dead (had mild neurological signs until 8 d.p.i.). The remaining four rabbits had only mild neurologic signs and no seizures; two of them were sacrificed at 10 d.p.i. and the other two at 12 d.p.i. (Tables 1 and 2).

\section{Virus isolation}

The results of virus isolation from nasal swabs and different brain regions are presented in Table 1. At 2 and 4 d.p.i., BHV-5 was isolatd from nasal swabs (Table 1). At 6 d.p.i. and thereafter, no virus could be isolated from nasal swabs.

In the brain, BHV-5 was isolated only from the olfactory bulb of rabbit \#2 $\left[7.6 \times 10^{2}\right.$ plaque forming unit (PFU)/g] and rabbit \#6 $\left(3.4 \times 10^{2} \mathrm{PFU} / \mathrm{g}\right)$ at 4 and 6 d.p.i., respectively. At 8 d.p.i., rabbit \#7 had high titers of virus in the olfactory bulb $\left(8.0 \times 10^{2} \mathrm{PFU} / \mathrm{g}\right)$, anterior $\left(6.0 \times 10^{2} \mathrm{PFU} / \mathrm{g}\right)$ and posterior $(5 \times$ $10^{3} \mathrm{PFU} / \mathrm{g}$ ) cortices, and the midbrain/diencephalon $\left(1.8 \times 10^{2} \mathrm{PFU} / \mathrm{g}\right)$. Virus also was isolated from the pons and medulla, but only after repassage of the infected cells. Rabbit \#13 had virus in the anterior $\left(2 \times 10^{1} \mathrm{PFU} / \mathrm{g}\right)$ and posterior $\left(2.4 \times 10^{3} \mathrm{PFU} / \mathrm{g}\right)$ cortices and in the pons/medulla $\left(2 \times 10^{1} \mathrm{PFU} / \mathrm{g}\right)$. In rabbit \#8, which was found dead at 9 d.p.i., virus was isolatd only from the anterior $\left(5.4 \times 10^{2} \mathrm{PFU} / \mathrm{g}\right)$ and posterior $\left(1 \times 10^{4} \mathrm{PFU} / \mathrm{g}\right)$ cortices.

Table 1 Virus isolation from nasal swabs and brain tissues

\begin{tabular}{|c|c|c|c|c|c|c|c|c|c|c|}
\hline \multirow[b]{2}{*}{$\begin{array}{l}\text { Rabbit } \\
\text { \# }\end{array}$} & \multirow[b]{2}{*}{$\begin{array}{l}\text { Neurological } \\
\text { signs }\end{array}$} & \multirow[b]{2}{*}{$\begin{array}{l}\text { Day died/ } \\
\text { killed (d.p.i.) }\end{array}$} & \multirow{2}{*}{$\begin{array}{l}\text { PFU's in } \\
\text { nasal } \\
\text { swab }\end{array}$} & \multicolumn{7}{|c|}{ Localization of virus in the brain } \\
\hline & & & & $\begin{array}{l}\text { Olfactory } \\
\text { bulb }\end{array}$ & $\begin{array}{c}\text { Anterior }^{a} \\
\text { cortex }\end{array}$ & $\begin{array}{c}\text { Posterior }^{b} \\
\text { cortex }\end{array}$ & $\begin{array}{c}\text { Midbrain/ } \\
\text { Diencephalon }\end{array}$ & $\begin{array}{c}\text { Pons/ } \\
\text { Medulla }\end{array}$ & Cerebellum & $\begin{array}{l}\text { Trigeminal } \\
\text { ganglion }\end{array}$ \\
\hline 2 & no & 2 & 45 & - & - & - & - & - & - & - \\
\hline 4 & mild & 4 & 7 & ++ & - & - & - & - & - & - \\
\hline 6 & mild & 6 & - & ++ & - & - & - & - & - & - \\
\hline 7 & seizure & 8 & - & ++ & +++ & +++ & + & $+^{*}$ & - & - \\
\hline 13 & seizure & 8 & - & - & + & +++ & - & + & - & - \\
\hline 8 & found dead & 9 & - & - & ++ & +++ & - & - & - & - \\
\hline 11 & mild & 10 & - & - & - & - & - & - & - & - \\
\hline 14 & mild & 12 & - & - & - & - & - & - & - & - \\
\hline
\end{tabular}

no= no clinical signs observed; mild signs are exemplified by hyperesthesia, head twitching and/or trembling; ${ }^{\text {ancludes olfactory }}$ tract, frontal cortex/cingulate cortex, and the anterior portion of piriform cortex; ${ }^{b}$ includes temporal, piriform parietal, occipital, and entorhinal cortices, amygdala and hippocampus; $-=$ no virus detected after repassage; $+=10^{1}-10^{2} \mathrm{PFU} / \mathrm{g}$ of tissue; $++=10^{2}-$ $10^{3} \mathrm{PFU} / \mathrm{g} ;+++=10^{3}-10^{4} \mathrm{PFU} / \mathrm{g} .+^{*}=\mathrm{CPE}$ noted after repassage of sample. 
Table 2 Presence and location of BHV-5 virus antigen within the rabbit brain following intranasal inoculation

\begin{tabular}{|c|c|c|c|c|c|c|c|c|c|c|c|c|}
\hline \multirow{2}{*}{$\begin{array}{l}\text { Rabbit } \\
\#\end{array}$} & \multirow{2}{*}{$\begin{array}{l}\text { Neurological } \\
\text { sign }\end{array}$} & \multirow{2}{*}{$\begin{array}{c}\text { Days } \\
\text { killed (d.p.i.) }\end{array}$} & \multicolumn{10}{|c|}{ Localization of virus in the brain } \\
\hline & & & $O B$ & Pir & Hippo & Amyg & $C G$ & $L C$ & $D R$ & $L D T$ & Cere & $T G$ \\
\hline 1 & no & 2 & - & - & - & - & - & - & - & - & - & $t^{*}$ \\
\hline 3 & mild & 4 & ++ & - & - & - & - & - & - & - & - & $+*$ \\
\hline 5 & mild & 6 & ++ & - & - & - & - & - & - & - & - & + \\
\hline 10 & seizure & 8 & ++ & ++++ & ++++ & +++ & +++ & + & ++ & + & - & $t^{*}$ \\
\hline 15 & seizure & 8 & ++ & ++++ & ++++ & +++ & +++ & + & ++ & - & - & $+^{*}$ \\
\hline 12 & seizure & 9 & ++ & ++++ & ++++ & +++ & +++ & + & ++ & - & - & - \\
\hline 16 & mild & 10 & - & - & - & - & - & - & - & - & - & - \\
\hline 9 & mild & 12 & - & + & - & + & - & - & - & - & - & - \\
\hline
\end{tabular}

$-=$ no labeling, $+=1-25$ labeling cells, ${ }^{*}=$ less than half of the grading range $++=25-150$ labeling cells, $+++=150-500$ labeling cells, $++++=>500$ labeling cells per field at $5 \times$ magnification. Abbreviations: d.p.i., days postinfection; OB, olfactory bulb; Pir, piriform cortex; Hippo, hippocampus; Amyg, amygdala; CG, cingulate cortex; LC, locus coeruleus; DR, dorsal raphe; LDT, lateral dosal tegmentum; Cere, cerebellum; TG, trigeminal ganglion.
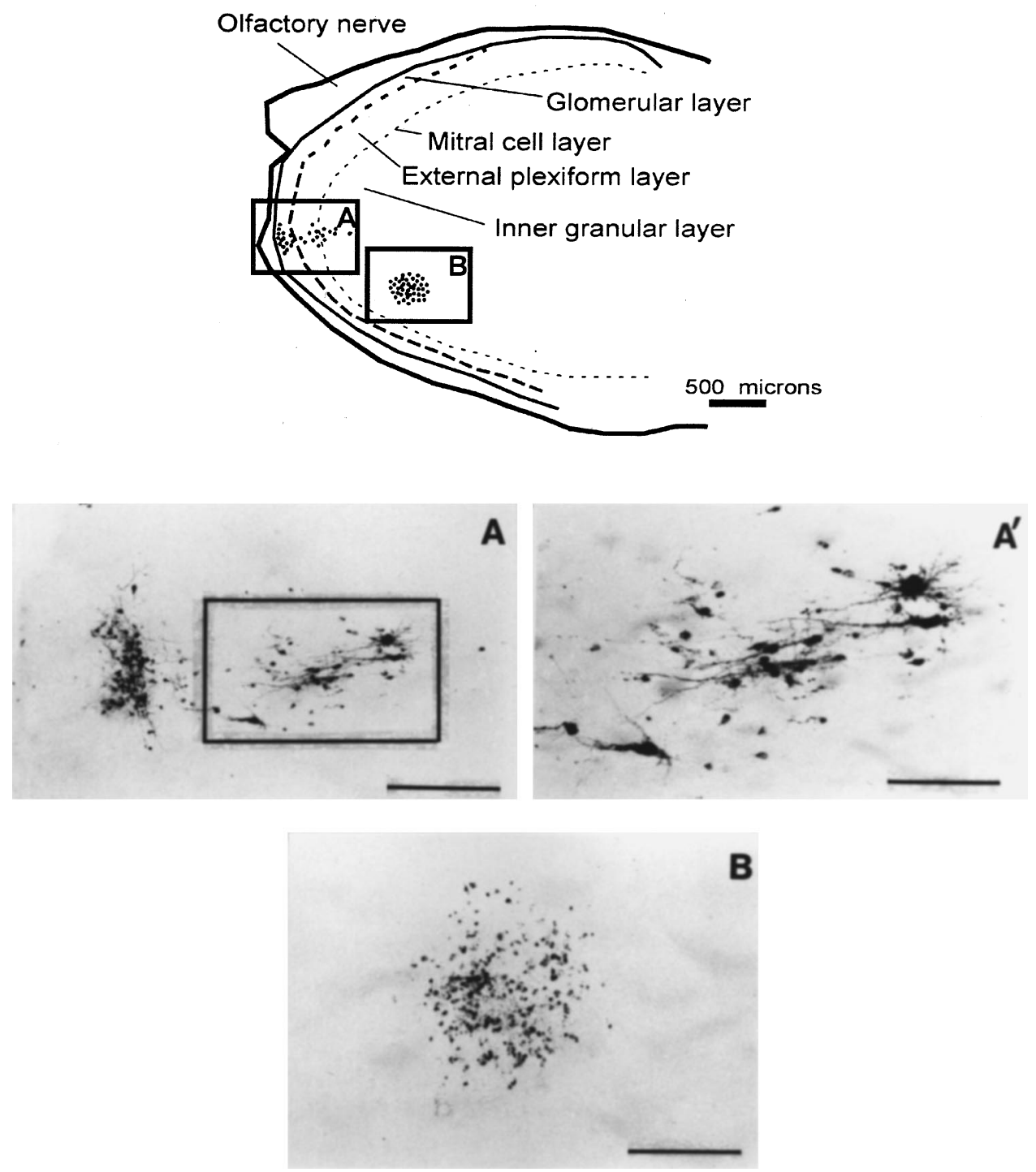

Figure 1 Localization of BHV-5 specific antigen in the main olfactory bulb at 4-6 d.p.i. Line drawing of the olfactory bulb (sectioned in sagittal plane). Frames indicate areas shown in photographs. Note that the immunostained neurons were indicated by dots. Immunostained cells had dense black precipitate over the cell nucleus. (A) At 4 d.p.i., immunostained neurons in the glomerular layer, the external plexiform, mitral cell layer and inner granular neurons. (A') Detail of boxed area under higher power magnification. (B) At 6 d.p.i., immunostained neurons in the inner granular neurons. Scale bars: $200 \mu \mathrm{m}$ (A and B), $100 \mu \mathrm{m}\left(\mathbf{A}^{\prime}\right)$. 
Virus was not isolated from any sections from the rabbits with mild neurological signs sacrificed at 10 and 12 d.p.i. Virus isolation results were negative from the trigeminal ganglion or cerebellum of all the rabbits, at all time points.

\section{Histopathological features}

In sections obtained at 2-6 d.p.i., no significant histological lesions were present in any of the regions of the brain that were examined. At 8 d.p.i., scattered neuronal necrosis and lymphocytic perivascular infiltrates occurred infrequently in the olfactory bulb. These lesions were most prominent and numerous in the caudal portions of the bulb. The piriform/entorhinal and frontal/cingulate cortices and hippocampus had locally extensive regions of moderate to severe lymphocytic meningo-encephalitis and perivascular cuffing in associa- tion with extensive zones of neuronal necrosis, gliosis, and rarefaction of the neuropil (data not shown).

Time course and antigen localization by immunocytochemistry

The location and extent of virus infection in neurons of the CNS and TG, as detected by immunocytochemistry, are summarized in Table 2. At 4 d.p.i., when the rabbits showed mild neurological signs (hyperaesthesia and headtwitching), viral antigens were detected in neurons of the glomerular, external plexiform, and mitral cell layers of the olfactory bulb (Figure 1A and Table 2). Additionally, the fibers of infected neurons in the external plexiform and mitral cell layers contained antigen (Figure 1A'). At 6 d.p.i., viral antigens were detected in all of the above areas
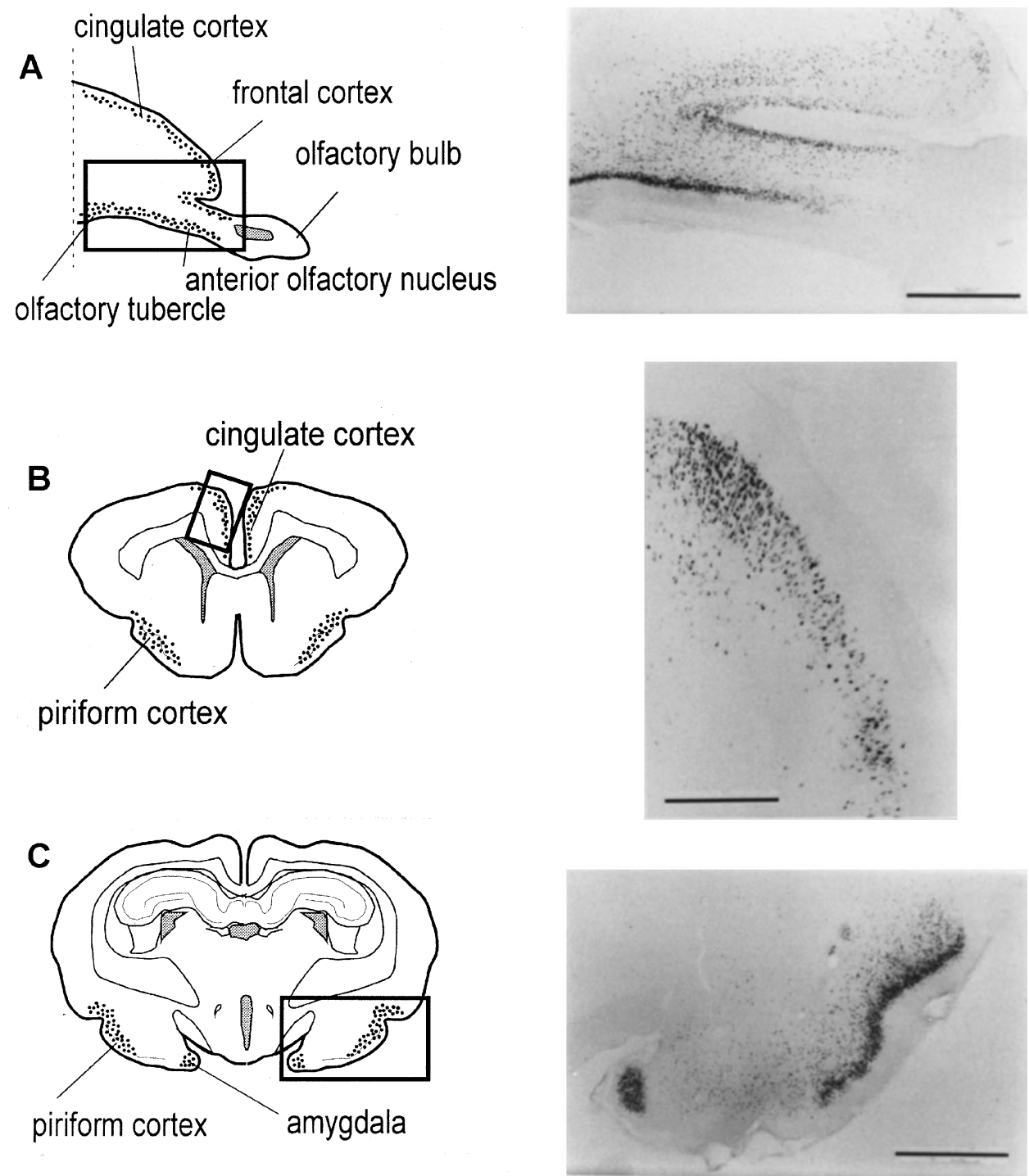
as well as in the inner granular layer (Figure 1B). More neurons over a greater area were affected in the main olfactory bulb.

The distribution of infected neurons after 8 d.p.i. is shown in Figure 2. At 8 and 9 d.p.i., virus-infected neurons were detected throughout the olfactory pathway. Many stained neurons ( $>150-500 /$ field at $5 \times$ magnification) were present in the anterior olfactory nucleus and olfactory tubercle (Figure 2A), frontal/cingulate and piriform cortices (Figure 2A, B and C), amygdala (Figure 2C), and hippocampus (Figure 2D). In the frontal/cingulate and piriform/entorhinal cortices, neurons of the pyramidal and polymorph cell layers (layers 4 and 5 in frontal and entorhinal cortices, and layers 2 and 3 in piriform and cingulate cortices) were infected. In the dentate gyrus and hippocampus, neurons in the granular and pyramidal cell layers, respectively, had the most staining. Neurons in the dorsal raphe (Figure 2E) also had dense staining; however, the number of neurons stained was comparatively lower (50-100 infected neurons/field) than in the above-mentioned structures. Positively stained regions in the locus coeruleus and the lateral dorsal tegmentum had approximately 5-10 infected neurons/field (Figure $2 \mathrm{~F}$ and Table 2). In case of one rabbit (\#10), 10-20 infected neurons/field (data not shown) were present in the central raphe
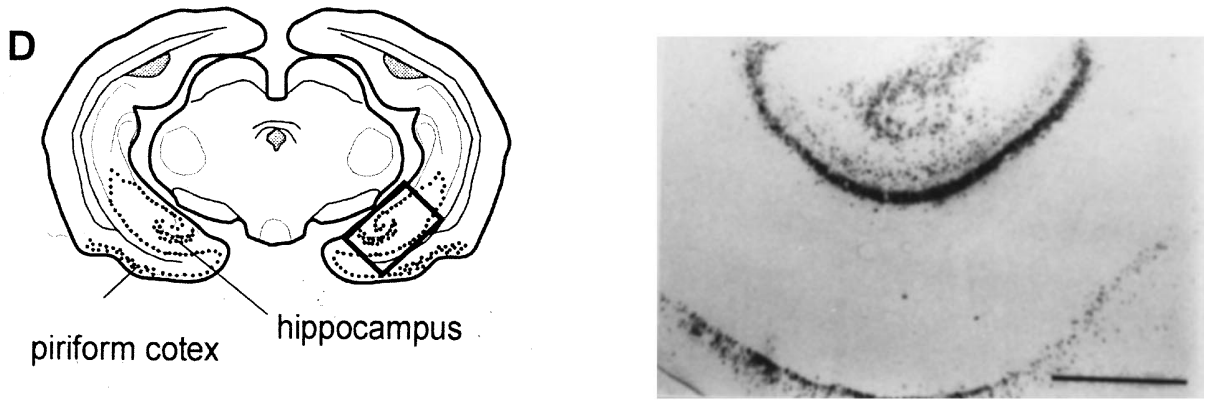

$\mathbf{E}$
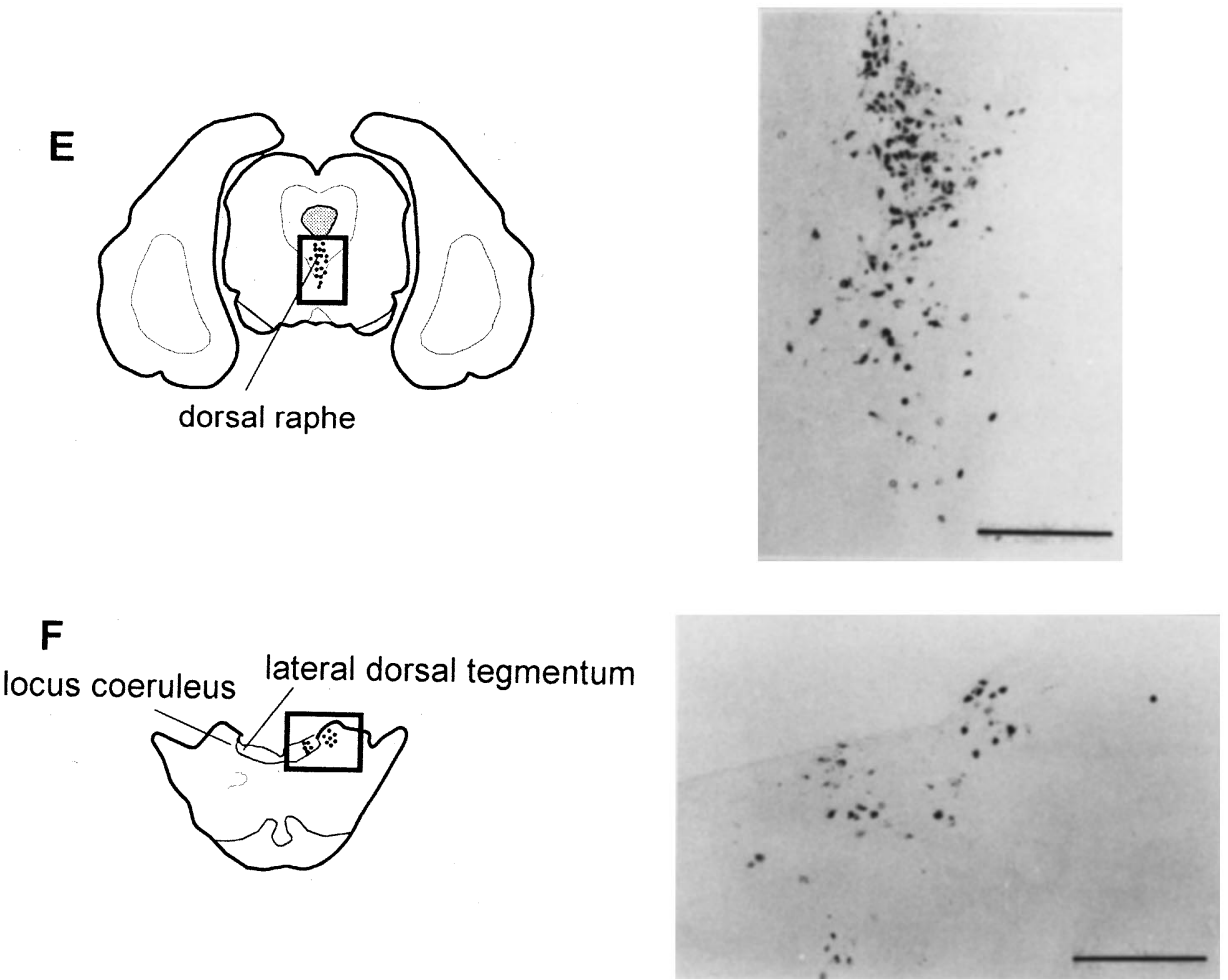

Figure 2 Localization of BHV-5 specific antigen in the rabbit brain at 8 d.p.i. Schematic representation of the rabbit brain depicting the CNS distribution of BHV-5-positive neurons (black dots indicate infected areas). Frames indicate areas shown in photographs. Bright-field photomicrographs show immunostained neurons (indicated by dense black precipitate over the cell). (A) Lateral olfactory tubercle, frontal cortex and piriform cortex (B) cingulate cortex, (C) piriform cortex and amygdala, (D) hippocampus, (E) dorsal raphe, (F) locus coeruleus and lateral dorsal tegmentum. Scale bars: $1600 \mu \mathrm{m}$ (A and C), $400 \mu \mathrm{m}$ (B, D, E and F). 

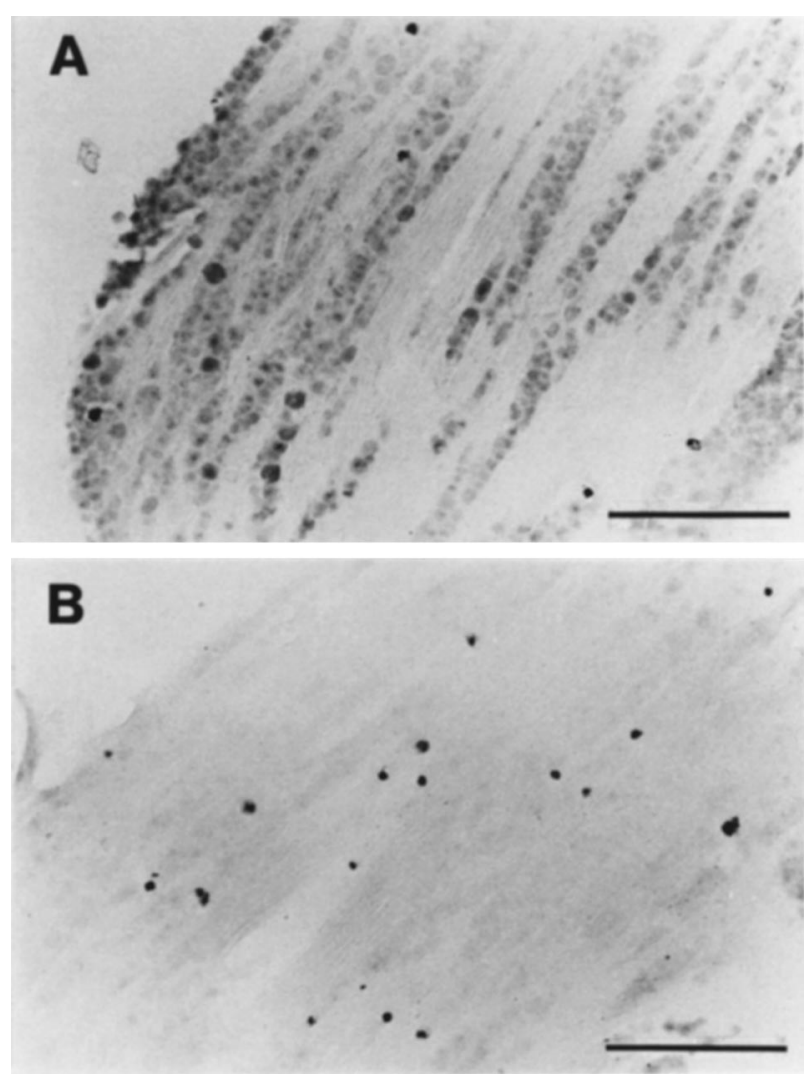

Figure 3 Immunostained neurons in the trigeminal ganglion in the rabbit. (A) Infected neurons in trigeminal ganglion (TG) at 4 d.p.i. (B) Infected neurons in TG after 6 d.p.i. Note that the processes of infected neurons in the TG did not stain. Scale bar: $200 \mu \mathrm{m}$. nucleus (medial part) and in the parabrachial nucleus. At 10 d.p.i., rabbit \#16 had no stained neurons. However, at 12 d.p.i., rabbit \#9 had a few stained neurons in the piriform/entorhinal cortices and amygdala. At 2, 4, 6, and 8 d.p.i., 3-10 infected neurons per field were detected within the trigeminal ganglion. The staining pattern in the trigeminal ganglion was intracellular; dendrites or axons of infected cells were not stained (see Figure 3). No stained neurons were present in the thalamus, hypothalamus, pontine and spinal nuclei of the trigeminal nerve, or cerebellum of any infected rabbits.

\section{Discussion}

The results of this study indicate that invasion and sequential spread of BHV-5 within the rabbit brain, following intranasal inoculation, are predominantly via the olfactory pathway. Neurological signs occurred following viral invasion and the development of lesions in the third and fourth order neuronal structures of the olfactory pathway.

\section{Olfactory and trigeminal pathways}

The olfactory pathway includes multiple neuronal projections (Brodal, 1969; Jenkins, 1978; Lohman and Lammers, 1967). The first neuronal level consists of the olfactory receptor cells, which are located among the nonneuronal cells of the olfactory epithelium. The receptor cells of the olfactory epithelium are bipolar neurons whose

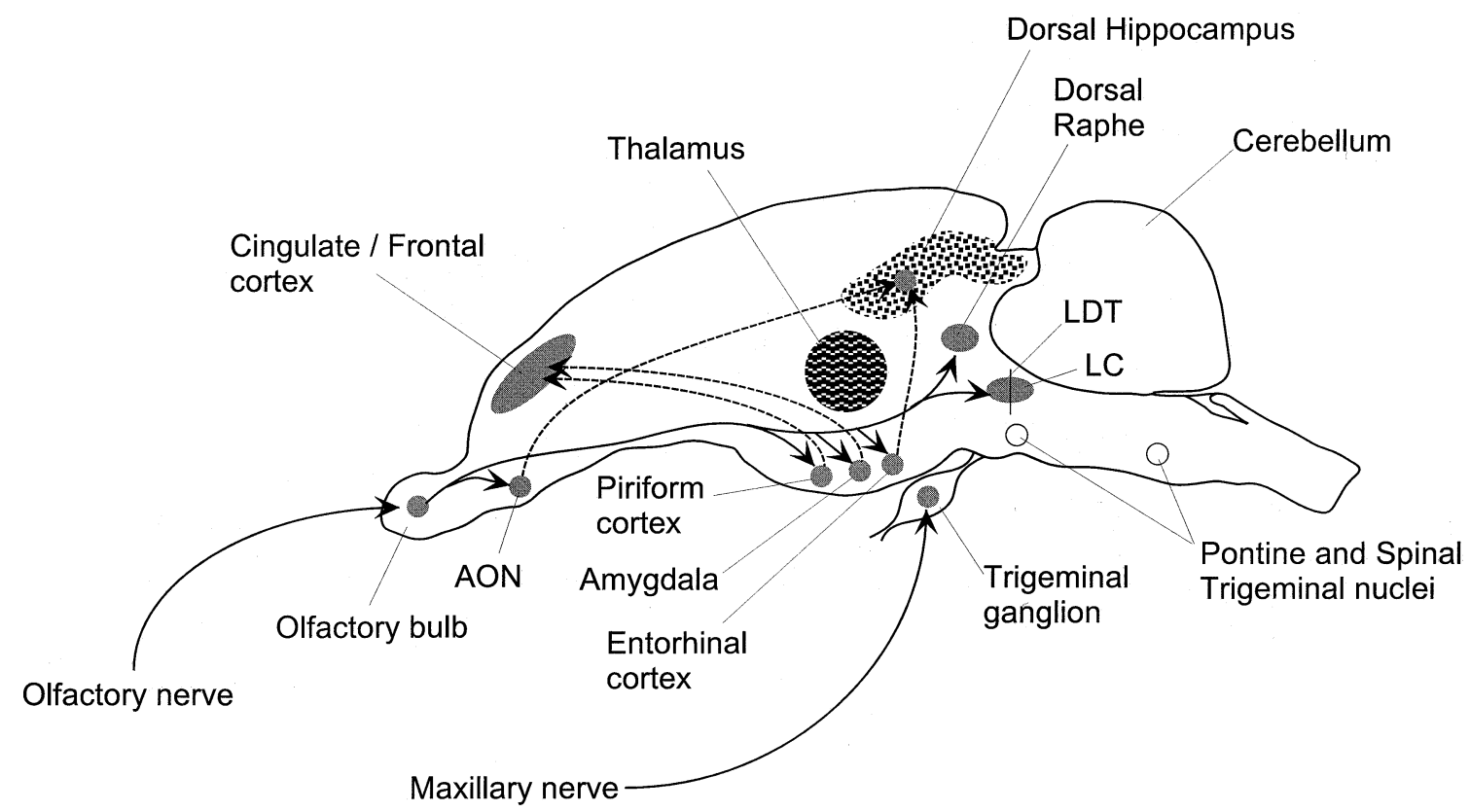

Figure 4 Schematic of proposed route and viral spread in the olfactory and trigeminal pathways after intranasal instillation. Solid lines indicate the structure connected directly to the olfactory bulb. Broken lines indicate the structure connected indirectly to the olfactory pathway. 
dendrites are in contact with the external environment (Frisch, 1967; Cuscheri and Bannister, 1975). These neurons are unique, because they are exposed directly to the environment and can incorporate protein instilled into the cavity by endocytosis (Kristensson and Olsson, 1971). They can be infected by neurovirulent viruses without prior replication in the surrounding epithelial cells (Lafay et al, 1991). Axons of these receptor neurons terminate in the glomerular layer of the main olfactory bulb (MOB) where they synapse with the dendrites of periglomerular cells, the tufted cells, and the mitral cells (second order neurons). The inner granular neurons (third neuronal level) make reciprocal synapses with the dendrites of mitral/brush cells (tufted neurons) (Halasz and Shepherd, 1983). In addition, the axons of both mitral and brush neurons leave the olfactory bulb and terminate in other structures of the brain, among which are the anterior olfactory nucleus (AON), lateral olfactory tubercle (LTu), piriform cortex, entorhinal cortex, amygdala, and dorsal raphe. These areas represent the third order neurons of the olfactory pathway. In addition, reciprocal projections from the AON, piriform cortex, amygdala, entorhinal cortex, dorsal raphe, lateral dorsal tegmentum (LDT), and locus coeruleus (LC) terminate in the olfactory bulb (Shipley et al, 1994).

The major inputs to the dentate gyrus and to the CA1 and CA 3 regions of the hippocampus are from the entorhinal cortex (fourth order neuronal connections). The dentate gyrus and cells of CA3 do not project back to the entorhinal cortex. However, the dentate gyrus and CA3 region project back to the CA 3 and CA 1 regions, respectively. The CA1 region of the hippocampus projects back to the entorhinal cortices. Additionally, the CA region of the hippocampus projects to the AON, thus connecting the hippocampus and the dentate gyrus reciprocally and indirectly to the olfactory pathway (Amaral and Witter, 1994). Similarly, efferent projections from the cingulate/frontal cortex (fourth order neurons) project to the piriform cortex and amygdala, thus connecting them indirectly to olfactory structures (Zilles and Wree, 1994).

The trigeminal pathway also contains multiple neuronal levels (Jenkins, 1978). The main sensory innervation of the nasal mucosa is mediated by branches of the maxillary nerve, which represent the distal dendrites of pseudo-unipolar cells of the trigeminal ganglion (Getty, 1975). The unipolar neurons of the trigeminal ganglion represent the first neuronal level of the trigeminal pathway. Axons of these neurons extend to the principal (pontine) nucleus and spinal nucleus of the trigeminal nerve (second order neurons) located in the pons and medulla oblongata, respectively (Jenkins, 1978). Axons arising from the second order neurons extend into the thalamus and/or cerebellum (third order neurons). Axons of the third order neurons in the thalamus extend into the cerebral cortex (Jenkins, 1978).

$B H V-5$ invades the CNS via the olfactory pathway The route of invasion of BHV-5 into the CNS is depicted in Figure 4. Following BHV-5 inoculation of the paranasal sinus of rabbits, immunocytochemically stained neurons containing virus specific antigens were present in the MOB (second order neurons) as early as 4 d.p.i. At 6 d.p.i., the number of stained neurons in the olfactory bulb increased, and viral antigen was present in deeper olfactory neurons. By 8 d.p.i. when the rabbits had severe neurological signs and histologic lesions, a substantial number of third and/or fourth order neurons in the AON, LTu, piriform/entorhinal cortex, amygdala, and dorsal raphe contained viral antigen. With the exception of LTu, all of these areas project to the MOB via efferent connections (Shipley et al, 1994). Thus, the virus appears to spread retrogradely to AON, piriform/entorhinal cortex, amygdala, and dorsal raphe but anterogradely to LTu (Figure 4). Immunostained neurons were also present in the LC and LDT (third and/or fourth order neurons). These two areas project to the MOB (Herrero et al, 1991; McLean et al, 1993). Thus, the virus spread retrogradely to these two areas (Figure 4). By $8-9$ d.p.i., fourth order neurons in the frontal/cingulate cortices, dentate gyrus, and hippocampus contained viral antigen that most likely was spread from the AON, piriform/entorhinal cortex, and amygdala (Figure 4). The alternative route of CNS invasion, the trigeminal pathway, did not appear to be involved in this study. In the trigeminal pathway, 2-10 stained nerve cell bodies were present in the trigeminal ganglion from 2-8 d.p.i. The virus most likely reached these neurons by retrograde movement via the maxillary branch of the trigeminal nerve. However, further spread to the pontine and spinal trigeminal nuclei (second order neurons in the trigeminal pathway) of the pons and medulla, respectively, did not occur. In addition, the staining of TG neurons was restricted to the cell bodies only and not their processes. In contrast, staining in the olfactory pathway consistently occurred in both nerve fibers and nerve cell bodies. The failure to isolate virus from the TG and the lack of staining in nerve cell processes suggests that the virus did not replicate efficiently in the neurons and probably was not transported out of the trigeminal ganglion.

\section{Neurological signs correlate with the viral spread in} the brain

In this study, viral spread and replication correlated well with the progression of neurological signs. Mild neurological signs appeared at 4 and 6 d.p.i. and were associated with immunostaining of neurons in the main olfactory bulb (glomeruli, 
external plexiform, mitral cells, and inner granular neurons). Virus could be isolated only from the olfactory bulbs, and no histopathological lesions were present. Severe neurological signs at 8 d.p.i. were associated with massive numbers of stained neurons in the piriform cortex, amygdala, cingulate cortex, and hippocampus. Virus was isolated in high titers, and histopathologic lesions consisting of neuronal necrosis and lymphocytic meningoencephalitis were prominent.

These data suggest that infection of the anterior olfactory nucleus, piriform and cingulate/frontal cortices, amygdala, hippocampus, and dentate gyrus is responsible for the development of severe neurological signs. The hippocampus, amygdala, and piriform/entorhinal cortices are involved when limbic seizures are induced by the injection of a cholinergic muscarinic antagonist (Motte et al, 1998). The hippocampus also could be the primary structure involved in the generation of measles virus-induced seizures (Urbanska et al, 1997). The disruption of cellular metabolism by viral replication in these regions may have contributed to the seizures observed in these rabbits (Halliday, 1975).

When an animal shows seizures, that animal usually would die within 8-12 h. If an animal was found to have severe seizures, it was euthanized within $2-3 \mathrm{~h}$ (as mandated by our animal care committee). Thus, the animals killed at 10 and 12 days did not show seizures at early times, but showed mild neurological signs exemplified by hyperaesthesia, trembling, head twitching, etc. In our previous paper, we reported that $20-30 \%$ of the animals show only a mild form of infection and usually survive (Chowdhury et al, 1997). In histopathology, the brains of these animals would show immune response to virus infections characterized by perivascular cuffing, nodular gliosis, etc. the virus isolation and immunohistochemistry results may or may not be positive depending on virus load. It is possible that in these animals the virus has gone latent in the CNS - this question was not investigated here. Thus, the question of whether virus has gone latent in the animals that survived $>10$ days has not been addressed in this paper.

Factors affecting neuroinvasiveness in olfactory and trigeminal pathways for other neurovirulent viruses Other neurovirulent viruses invade the CNS following intranasal deposition via the olfactory pathway, e.g., vesicular stomatitis virus (VSV) (Lundh et al, 1987, 1988) and murine hepatitis virus (MHV) (Barthold, 1988) or via both the olfactory and trigeminal pathways, e.g., herpes simplex virus type 1 (HSV1) (McLean et al, 1989; Barnett et al, 1994) and pseudorabies virus (Barbic et al, 1994; Kritas et al, 1994a,b). Several factors may determine whether the CNS will be invaded by a neurovirulent virus along cranial or peripheral nerves. These include a primary cycle of virus replication in the innervated area, viral attachment to axonal or dendritic terminals of the primary neurons, multiplication and vectorial transport of viral components in the nerve cells and their processes, and restriction of virus spread by the host animal defense mechanisms against the infection. Affinity for the olfactory or respiratory epithelium and the nature of viral budding are critical factors in the differential neuroinvasive properties of vesicular stomatitis virus (VSV) and Sendai virus (SV) (Lundh et al, 1987). Neuroinvasive VSV causes extensive infection of the olfactory epithelium with minimal involvement of the respiratory epithelium. Conversely, nonneuroinvasive SV causes extensive infection of the respiratory epithelium with only minimal infection of the olfactory mucosa. Differences in viral budding account for some neuroinvasive potential. The VSV buds from the basolateral surfaces of supporting cells and olfactory neurons, but not from their apical surfaces or the ciliated bulbous endings of the olfactory neuron dendrites, thus favoring neuroinvasion. The SV buds only from the apical surface of respiratory epithelial cells and is released into the air passage without invasion into the olfactory bulbs (Lundh et al, 1987).

Following intranasal inoculation, swabs obtained from the nasal turbinates and nasal vestibular regions yielded higher quantities of BHV-1, than of BHV-5 (Chowdhury, unpublished data). However, only BHV-5 invades the CNS via the olfactory pathway. When inoculated intracerebrally, both BHV-1 and 5 are equally neurovirulent (Chowdhury, unpublished results). This implies that differences exist in BHV-1 and BHV-5 interactions with the olfactory receptor neurons that may be important in the neuropathogenesis of BHV-5. Alternatively, the viruses may differ in their ability to spread anterogradely from the olfactory receptor neurons (first order neurons) to the olfactory bulb (second order neurons). However, the failure of BHV-5 to spread anterogradely from TG to pontine and spinal nuclei is not consistent with this assumption.

In comparison to other sensory pathways, the olfactory nervous pathway exhibits several unique features. First, the olfactory receptor cells (first order neurons) are the only known neurons that are replaced in postnatal life (reviewed in Cormack, 1987). Additionally, the olfactory receptor cells provide a direct connection between the brain and the external environment, a feature lacking in other neural pathways, including the trigeminal pathway where external tissues or synapses interrupt the route towards the CNS.

\section{Natural pathogenesis of BHV types 1 and 5}

BHV-1 and BHV-5 are related antigenically and genetically, however, they differ markedly in their ability to cause neurological disease in calves 
(Belknap et al, 1994). BHV-1 causes respiratory and genital infections and occasionally abortion and enteritis in cattle (Wyler et al, 1989). BHV-1 has been divided into two subtypes based upon DNA restriction profiles and pathogenic properties into the respiratory, abortigenic subtype (IBR,BHV-1.1) and the non-abortigenic, genital subtype (IPV,BHV-1.2). BHV-5, also known as bovine encephalitic herpesvirus (BEHV), is the causative agent of a fatal meningo-encephalitis in calves (Engels et al, 1987; Bulach and Studdert, 1990). Calves experimentally inoculated, intranasally, with BHV-5 showed evidence of extensive widespread meningo-encephalitis and neural necrosis and viral replication in the brain. In contrast, BHV-1 inoculated calves had no brain lesions (Belknap et al, 1994). In previous work, we have demonstrated that in the rabbit model, BHV-5 was capable of producing a fatal meningoencephalitis with severe neurological signs and BHV-1 was not neurovirulent in rabbits under similar experiental conditions (Chowdhury et al, 1997). Based upon the results of the present paper and those obtained previously, we suggest that BHV1 and BHV-5 differ in their affinity for olfactory receptor neurons (ORN). BHV-5 may have an affinity for the specific receptors on the first order olfactory neurons, whereas BHV-1 does not. In addition, our results suggest that the TG is not important for the neuropathogenic effects of BHV-5 in the rabbit model. If these assumptions are true, then the mechanism by which BHV-5 invades the CNS may be unique and different from that of VSV, HSV-1, and PRV because these viruses penetrate the CNS via TG pathway, in addition to the olfactory pathway.

\section{Materials and methods}

Virus and cell cultures

The BHV-5 strain (TX-89) isolated from a case of viral encephalitis (d'Offay et al, 1993) was used for the study. Stocks of virus were prepared in MadinDarby bovine kidney (MDBK) cells grown in Dulbecco's modified Eagle's medium (DMEM) supplemented with $10 \%$ fetal bovine serum (FBS). Virus was titrated by standard plaque assay, aliquoted, and frozen at $-80^{\circ} \mathrm{C}$.

\section{Animals}

Sixteen, 4-week-old New Zealand White rabbits (500-600 g body weight) were used (Myrtles Rabbitry, Thomson Station, TN, USA). Rabbits were maintained in laboratory isolation cages in our vivarium throughout the experiment with food and water freely available. All procedures were approved by the Kansas State University Institutioanl Animal Care and Use Committee.

\section{Rabbit inoculation}

Rabbits were anesthetized by intramuscular injection of ketamine $(10 \mathrm{mg} / \mathrm{kg})$ and xylazine $(5 \mathrm{mg} / \mathrm{kg})$ and infected intranasally with BHV-5 virus $\left(2 \times 10^{7} \mathrm{PFU} / 0.3 \mathrm{ml}\right.$ per nostril) (Chowdhury et al, 1977). Following infection, rabbits were observed three times daily for clinical signs (Chowdhury et $a l, 1997)$. At least, two rabbits were sacrificed at 2,4 , 6, 8, 10 and 12 d.p.i. or when they developed severe neurological symptoms. At each time period, one rabbit was used for virus isolation (left brain hemisphere) and histopathological examination (right brain hemisphere) (rabbits \#2, 4, 6, 7, 8, 11, 13,14 ), and the other rabbit was perfused (rabbits $\# 1,3,5,9,10,12,15,16)$ for immunocytochemistry.

\section{Virus isolation}

Nasal swabs were obtained at each time point for virus isolation. A plain cotton-tip swab was inserted into each nasal vestibule and nasal turbinate and rotated three times against the mucosa. Virus was eluted from the swabs in $1 \mathrm{ml}$ of sample medium for $1 \mathrm{~h}$ at $4^{\circ} \mathrm{C}$, filtered, and assayed by standard plaque assay.

The left brain hemisphere was dissected into six regions: the olfactory bulb; midbrain and diencephalon (thalamus and hypothalamus); anterior cortex (frontal area, olfactory tract, cingulate cortex, and the anterior portion of the piriform cortex); posterior cortex (temporal area, piriform area, entorhinal area, parietal area, occipital area, and hippocampus); pons and medulla; and cerebellum. The left trigeminal ganglion and each of the six regions were homogenized separately for virus isolation (Chowdhury et al, 1997). All cultures without evidence of cytopathic effect were repassaged to confirm the absence of the virus.

\section{Immunocytochemistry}

Virus-specific antigens were detected using immunocytochemistry (Weiss and Chowdhury, 1998). Briefly, each rabbit was deeply anesthetized and transcardially perfused, using a peristaltic pump, with $500 \mathrm{ml}$ of heparinized $(3 \mathrm{IU} / \mathrm{ml})$ isotonic saline, followed by $2 \mathrm{l}$ of $10 \%$ buffered neutral formalin. The whole brain and trigeminal ganglion were removed, fixed overnight in $10 \%$ buffered neutral formalin, and transferred to $20 \%$ sucrose in PBS for cryoprotection. The trigeminal ganglia were embedded in $10 \%$ gelatin. The tissues were frozen on dry ice, and serial $40 \mu \mathrm{m}$ sections were made using a sliding microtome (American Optical Corp. model 860, Buffalo, NY, USA). Every sixth serial section from the brain and every section from the trigeminal ganglion were processed for immunocytochemistry. Endogenous peroxidase was inactivated by incubation with $0.3 \%$ hydrogen peroxide for $30 \mathrm{~min}$ followed by five washes ( $5 \mathrm{~min} / \mathrm{wash}$ ) with PBS containing 2\% Triton X-100 (PBS-TX). After $30 \mathrm{~min}$ incubation in $5 \%$ inactivated horse serum in PBS-TX, the tissues were incubated overnight at $4{ }^{\circ} \mathrm{C}$ with polyclonal bovine serum directed against BHV-5 (1:10000 in PBS-TX) 
(Chowdhury et al, 1997). Sections then were washed five times in PBS-TX and incubated for $3 \mathrm{~h}$ at room temperature with antibovine biotinylated antibody (Kirkegaard \& Perry Laboratories, Gaithesberg, MD, USA) diluted 1:400 in PBS-TX. After being washed three times with PBS-TX, tissues were processed with the avidin-biotinperoxidase procedure using Vectastain reagents (Vectastain Elite ABC kit; Vector Laboratories, Burlingame, CA, USA). Peroxidase was visualized by incubation with $0.05 \%$ (wt/vol) diaminobenzidine tetrahydrochloride (DAB; Sigma, St. Louis, MO, USA) and $0.01 \%$ (vol/vol) hydrogen peroxide in $175 \mathrm{mM}$ sodium acetate, $10 \mathrm{mM}$ imidazole, $\mathrm{pH}$ 7.2 (A/I buffer) for $2 \mathrm{~min}$. The reaction was stopped by washing with A/I buffer. Immunocytochemically stained sections were mounted on gelatin-coated slides, air dried, rinsed in distilled water, and dried overnight. The tissue was dehydrated in ethanol and cleared in xylene, and a coverslip was added with DPX mountant (Fluka, Ronkonkoma, NY, USA). Positive staining was detected by the presence of dense black precipitate over the cell.

\section{References}

Amaral DG, Witter MP (1994). Hippocampal formation. In: The Rat Nervous System. Paxinos G, (ed). Academic Press: San Diego, New York, pp 443-493.

Barbic N, Mettenleiter T, Ugolini G, Flamand A, Coulon $P$ (1994). Propagation of pseudorabies virus in the nervous system of the mouse after intranasal inoculation. Virology 204: 616-625.

Barnett EM, Jacobsen G, Evans G, Cassel M, Perlman S (1994). Herpes simplex encephalitis in the temporal cortex and the limbic system after trigeminal nerve inoculation. J Infect Dis 169: $782-786$.

Barthold SW (1998). Olfactory neural pathway in mouse hepatitis virus naso-encephalitis. Acta Neuropathol 76: $502-506$.

Belknap EB, Collins JK, Ayers VK, Schulteiss PC (1994). Experimental infection of neonatal calves with neurovirulent bovine herpesvirus type 1.3. Veterinary Pathol 31: $358-365$.

Brodal A (1969). Neurological Anatomy in Relation to Clinical Medicine, (2nd edn). Oxford University Press: London, p 283.

Bulach DM, Studdert MJ (1990). Comparative genome mapping of bovine encephalitis herpesvirus, bovine herpesvirus 1, and buffalo herpesvirus. Arch Virol 113: $17-34$.

Chowdhury SI, Lee BJ, Mosier D, Sur JH, Osorio FA, Kennedy G, Weiss ML (1997). Neuropathology of bovine herpesvirus type 5 (BHV-5) meningo-encephalitis in a rabbit seizure model. J Comparative Pathol 117: $295-310$.

Contreras RJ, Gomez MM, Norgren R (1980). Central origins of cranial nerve parasympathetic neurons in the rat. J Comparative Neurol 190: $373-394$.

Cormack D (1987). Ham's Histology, (9th edn). Lippincott: Philadelphia, pp 541-566.
To confirm immunocytochemical specificity, the primary antibody was eliminated from the protocol. Removal of the primary antibody completely eliminated positive immunocytochemical staining.

\section{Histopathology}

Tissues were fixed in $10 \%$ neutral buffered formalin for a minimum of $24 \mathrm{~h}$. Tissue sections from the regions of interest then were dehydrated in sequential alcohol washes and embedded in paraffin. Four, $6 \mu \mathrm{m}$ sections were cut, mounted on slides, stained with hematoxylin and eosin, overlaid with a coverslip, and observed microscopically for morphologic alterations.

\section{Acknowledgements}

This work was supported by USDA grants 9537204-2309 and 97-35204-4700 to SI Chowdhury. Published as Contribution 99-298-J, Kansas Agricultural Experiment Station.

Cuschieri A, Bannister LH (1975). The development of the olfactory mucosa in the mouse: electron microscopy. J Anat 119: 471-498.

d'Offay JM, Mock RE, Fulton RW (1993). Isolation and characterization of encephalitic bovine herpesvirus type 1 isolates from cattle in North America. Am J Veterinary Res 54: 534-539.

Engels M, Giuliani C, Wild P, Beck P, Loepf TM, Wyler R (1987). The genome of bovine herpesvirus 1 (BHV-1) strains exhibiting a neuropathogenic potential compared to known BHV-1 strains by restriction site mapping and cross-hybridization. Virus Res 6: 57-73.

Frisch D (1967). Ultra structure of mouse olfactory mucosa. Am J Anat 121 87-120.

Getty R (1975). Sisson and Grossman's: The Anatomy of the Domestic Animals. Saunders: Philadelphia, p 1372.

Halasz N, Shepherd GM (1983). Neurochemistry of the vertebrate olfactory bulb. Neuroscience 10: 579-619.

Halliday AM (1975). The neurophysiology of myoclonic jerking. In: Myoclonic Seizures. Charlton $\mathrm{MH}$, (ed). Excerpta Medica: Amsterdam, pp 1-15.

Herrero MT, Insansti R, Gonzalo LM (1991). Cortical projections from the laterodorsal and dorsal tegmental nuclei. A fluorescent retrograde tracing study in the rat. Neurosci Lett 123: 144-147.

Jenkins T (1978). Functional Mammalian Neuroanatomy. Lea \& Febiger: Philadelphia, p 225.

Knotts FB, Cook ML, Stevens JG (1974). Pathogenesis of herpetic encephalitis in mice after ophthalmic inoculation. I Infect Dis 130: 16-17.

Kristensson K, Olsson Y (1971). Uptake of exogenous proteins in mouse olfactory cells. Acta Neuropathol (Berlin) 19: $145-154$. 
Kritas SK, Pensaert MB, Mettenleiter TC (1994a). Invasion and spread of single glycoprotein deleted mutants of Aujeszky's disease virus (ADV) in the trigeminal nervous pathway of pigs after intranasal inoculation. Veterinary Microbiol 40: 323-334.

Kritas SK, Pensaert MB, Mettenleiter TC (1994b). Role of envelope glycoprotein gI, gp63 and gIII in the invasion and spread of Aujeszky's disease virus in the olfactory nervous pathway of the pig. J Gen Virol 75: 23192327.

Lafay F, Coulon P, Astic L, Saucier D, Richie D, Holley A, Flamand A (1991). Spread of the CVS strain of rabies virus and of the avirulent mutant Avo1 along the olfactory pathways of the mouse after intranasal inoculation. Virology 183: 320-330.

Lohman AH, Lammers HJ (1967). On the structure and fibre connections of the olfactory centers in mammals. In: Sensory Mechanisms. Zotterman Y, (ed), Elsevier: Amsterdam, London and New York, pp 65-82.

Lundh B, Kristensson K, Norrby E (1987). Selective infections of olfactory epithelium by vesicular stomatitis and Sendi viruses. Neuropathol Applied Neurobiol 13: $111-122$.

Lundh B, Löve A, Kristensson K, Norrby E (1988). Nonlethal infection of aminergic reticular core neurons: age-dependent spread of $t s$ mutant vesicular stomatitis virus from the nose. I Neuropathol Applied Neurobiol 47: $497-506$.

Martin X, Dolivo M (1983). Neuronal and transneuronal tracing in the trigeminal system of rat using the herpesvirus suis. Brain Res 273: 253-276.

McLean JH, Shipley MT, Bernstein DI (1989). Golgi-like, transneuronal retrograde labelling with CNS injections of herpes simplex virus type 1. Brain Res Bulletin 22: $867-881$.

McLean JH, Shipley MT, Bernstein DI, Corbett D (1993). Selective lesions of neural pathways following viral inoculation of the olfactory bulb. Expt Neurol 122: $209-222$.

Motte J, da Silva Fernandes MJ, Baram TZ, Nehlig A (1998). Spatial and temporal evolution of neuronal activation, stress and injury in lithium-pilocarpine seizures in adult rats. Brain Res 793: $61-72$.

Shipley MT, McLean JH, Ennis M (1994). Olfactory Systems. In: The Rat Nervous System. Paxinos G, (ed). Academic Press: San Diego, New York, pp 899926.

Spencer SE, Sawyer WB, Wada H, Platt KB, Loewy AD (1990). CNS projections to the pterygopalatine parasympathetic preganglionic neurons in the rat: a retrograde transneuronal viral cell body labeling study. Brain Res 534: 149-169.

Stroop WG, Rock Dl, Fraser NW (1984). Localization of herpes simplex virus in the trigeminal and olfactory system of the mouse central nervous system during acute and latent infection by in situ hybridization. $L a b$ Invest 51: $27-38$.

Switzer RC, De Olmos J, Heimer L (1985). Olfactory system. In: The Rat Nerve System. Vol 1. Paxinos G, (ed). Academy Press: Sydney, pp 1-36.

Tomlinson AH, Esiri MM (1983). Herpes simplex encephalitis: immunohistological demonstration of spread of virus via olfactory pathways in mice. $J$ Neurol Sci 60: $473-484$.

Tracey DJ (1985). Somatosensory system. In: The Rat Nerve System. Vol. 2. Paxinos G, (ed). Academy Press: Sydney, pp 129-152.

Urbanska EM, Chambers BJ, Ljunggren HG, Norrby E, Kristensson K (1997). Spread of measles virus through axonal pathways into limbic structures in the brain of TAP1 - / - mice. I Med Virol 52: 362-369.

Weiss ML, Chowdhury SI (1998). The renal afferent pathways in the rat: A pseudorabies virus study. Brain Res 812: $227-241$.

Wyler R, Engels M, Schwyzer M (1989). Infectious bovine rhinotracheitis/vulvovaginitis (BHV-1). In: Herpesvirus Disease of Cattle, Horses and Pigs. Wittman, G (ed), Kluwer Academic Publishers: Hingham, Massachusetts, pp 1-72.

Zilles K, Wree A (1994). Cortex: A real and laminar structure. In: The Rat Nervous System. Paxinos G, (ed). Academic Press: San Diego, New York, pp 649685. 